07,01

\title{
Механические и нелинейные упругие характеристики поликристаллического алюминиевого сплава AMg6 и нанокомпозита $n$-AMg6/C 60
}

\author{
() А.И. Коробов ${ }^{1}$, А.И. Кокшайский ${ }^{1, \uparrow, ~ В . М . ~ П р о х о р о в ~}{ }^{2}$, И.А. Евдокимов ${ }^{2}$, \\ С.А. Перфиилов ${ }^{2}$, А.Д. Волков ${ }^{1}$ \\ ${ }^{1}$ Московский государственный университет им. М.В. Ломоносова, \\ Москва, Россия \\ ${ }^{2}$ Технологический институт сверхтвердых и новых углеродных материалов, \\ Москва, Троицк, Россия \\ 『E-mail: aikor42@mail.ru
}

(Поступила в Редакцию 26 апреля 2016 г.)

\begin{abstract}
Экспериментально исследовано влияние наноструктурования на механические и нелинейные упругие характеристики поликристаллического алюминиевого сплава $\mathrm{AMg} 6$ и нанокомпозита $n-\mathrm{AMg} 6 / \mathrm{C}_{60}$. В образцах алюминиевого сплава $\mathrm{AMg} 6$ и нанокомпозита $n$ - $\mathrm{AMg} 6 / \mathrm{C}_{60}$ измерены механические характеристики и, ультразвуковым методом, все независимые коэффициенты упругости второго и третьего порядков. Коэффициенты упругости третьего порядка были определены методом Терстона-Браггера по результатам экспериментальных измерений зависимости скорости сдвиговых и продольных объемных акустических волн в исследуемых образцах от величины одноосного сжатия. Спектральным акустическим методом исследованы нелинейные упругие свойства и определены нелинейные акустические параметры этих материалов.
\end{abstract}

Образцы и исследования их механических характеристик выполнены в рамках госзадания Министерства образования и науки РФ на 2016 г. (проект № 3562). Ультразвуковые исследования были выполнены за счет гранта Российского научного фонда (проект № 14-22-00042).

\section{1. Введение}

Для изготовления изделий, предназначенных для промышленности, применяются более 150 сплавов алюминия. Сплав AMg6 относится к системе $\mathrm{Al}-\mathrm{Mg}-\mathrm{Mn}$ (включает: до 93.68\% алюминия, 5.8-6.8\% магния, 0.5-0.8\% марганца и прочие примеси) [1,2]. Он сочетает хорошие прочностные с высокими пластическими характеристиками, как при комнатной, так и при повышенных температурах, хорошо сваривается. Такое сочетание свойств обусловило широкое использование сплава AMg6 в авиакосмической индустрии, строительстве, автомобилестроении, а высокая коррозионная стойкость в различных средах, в том числе и в морской воде, объясняет его успешное применение в судостроении. Для улучшения механических свойств алюминиевых сплавов их предварительно подвергают механическому деформированию и тепловой обработке. Однако, повысить прочностные характеристики магнийсодержащего сплава AMg6 путем закалки не удается - этот сплав относится к термически не упрочняемым сплавам.

Одним из современных прогрессивных методов улучшения физико-механических свойств металлов и сплавов является наностуктурирование - формирование наноструктуры в объеме материала. В последние годы достигнут большой прогресс в разработке методов наноструктурирования, приводящих к новым, необычным сочетаниям свойств, таких, как высокая прочность и пластичность в сочетании с повышенной твердостью, рекордная усталостная долговечность, сверхпластичность и др. [3]. Так, в работе [4], методом равноканального углового прессования литого сплава AMg6 получен материал со средним размером зерна $400 \mathrm{~nm}$, механические свойства которого были значительно улучшены (предел прочности $\sigma_{\mathrm{B}}$ от $210 \mathrm{MPa}$ у литого сплава до $440 \mathrm{MPa}$, а удлинение до разрыва $\delta$ в 2 раза, до $25 \%$ при комнатной температуре). Еще более высокие значения механических характеристик нанокомпозитного, армированного углеродом сплава $\mathrm{AMg6}$, приготовленного по методу размола в шаровой мельнице с последующим экструдированием, получены в работе [5]. Предел прочности на растяжение в нанокомпозитном AMg6 увеличен до $\approx 500-700 \mathrm{MPa}$, а деформация при разрушении до 10.5-14.1\% соответственно при повышенной твердости, достигающей $1.5-1.7 \mathrm{GPa}$.

Значительное повышение прочности (и твердости) металлов и сплавов при их наноструктурировании хорошо описывается эмпирическим соотношением ХоллаПетча для зависимости между пределом текучести $\sigma_{y}$ и твердости $H$ и средним размером зерна $d[6-8]$ :

$$
\sigma_{y}=\sigma_{0}+K_{y} d^{-0.5}, \quad H=H_{0}+K_{H} d^{-0.5},
$$

где $d$ - размер зерна в поликристаллическом материале, $\sigma_{0}, H_{0}, K_{y}$ и $K_{H}$ - константы для данного материала.

Понятно, что механические характеристики (как и характеристики упругости) связаны между собой. Однако, нет простых, общих для всех поликристаллических материалов, соотношений между механическими свойствами (твердостью, пределом текучести, пределом 
прочности, относительным удлинением) и характеристиками упругости (модулем сдвига, модулем Юнга, коэффициентом Пуассона, модулем объемной упругости). Для установления таких соотношений требуется проведение на конкретных материалах совместных экспериментальных исследований механических и упругих свойств. В то же время существуют некоторые тенденции и конкретные эмпирические соотношения [9], справедливые, как правило, для высокомодульных, хрупких и твердых материалов, удовлетворяющих соотношению Пага между модулем сдвига $G$ и объемным модулем $B$ : $G / B>0.571[10,11]$.

Наиболее часто встречающаяся корреляция между модулем Юнга $E$ и модулем сдвига $G$ поликристаллических материалов и теоретической прочностью при растяжении $\sigma_{\text {th }} \cong E / 10$, при сдвиге $\sigma_{\text {sh }} \cong G / 2 \pi-G / 10$ [11].

Значения коэффициентов упругости второго порядка (КУВП) для наноматериалов практически не отличаются от таковых применительно к их исходным микрокристаллическим объектам. Однако это заключение верно лишь для материалов, у которых доля поверхностей раздела (отношение числа атомов на поверхности раздела к числу атомов в объеме) в общей наноструктуре не очень велика. При размере кристаллитов $\leq 10 \mathrm{~nm}$, когда эта доля составляет десятки процентов, значение упругих характеристик должно уменьшаться, следуя примерно аддитивному соотношению, из-за наличия внутренней пористости в наноструктурированном материале. Очевидно, что заметного снижения упругих характеристик можно избежать путем заполнения пустот стыков наночастиц материалом с высокими упругими и прочностными свойствами (т. е. формированием нанокомпозита), а при формировании химических связей заполняющего поры материала с поверхностью наночастиц возможно и повышение значений упругих модулей [12].

Для количественной оценки упругих свойств твердых тел используются коэффициенты упругости второго порядка $C_{i j k l}($ КУВП) и коэффициенты упругости третьего порядка $C_{i j k q r}$ (КУТП). КУВП характеризуют линейную зависимость напряжения от деформации твердого тела в законе Гука. Отклонения от линейной зависимости закона Гука определяется КУТП. КУТП количественно описывают ангармонические свойства кристаллической решетки: тепловое расширение, взаимодействие фононов, высокочастотное поглощение ультразвука. Эти коэффициенты позволяют рассчитать анизотропию параметра Грюнайзена. КУТП также используются для анализа взаимодействия акустических волн конечной амплитуды в твердых телах [13-16]. Остается открытым вопрос, как меняются при наноструктурировании КУТП? И какова связь между КУТП и другими механическими характеристиками поликристаллических материалов?

В структурно-неоднородных средах, в том числе в поликристаллических металлических сплавах наряду c упругой нелинейностью, связанной с ангармонизмом кристаллической решетки (классическая нелинейность), присутствует упругая структурная нелинейность (неклассическая нелинейность), обусловленная макроскопическими дефектами в твердых телах: микротрещинами, межзеренными границами, остаточными напряжениями, нарушением сплошности и т.д. Структурная нелинейность имеет локальный характер (определяется наличием указанных выше дефектов в конкретной области твердого тела) и может существенно превышать упругую нелинейность, связанную с ангармонизмом кристаллической решетки [16]. Основные физические механизмы структурной нелинейности рассмотрены в [17].

В $[18,19]$ была экспериментально установлена корреляция между величиной упругой нелинейности и прочностью материала. При этом эта корреляция наблюдалась как в структурно-неоднородных конструкционных материалах, так и в кристаллах. Поэтому исследование нелинейных упругих свойств материалов имеет не только фундаментальное, но и прикладное значение.

Для исследования нелинейных упругих свойств разработан ряд экспериментальных методов [14,20-22], среди которых широко используемые метод ТерстонаБраггера [20] и спектральный метод [14,21].

Коэффициенты упругости второго и третьего порядков в поликристаллическом сплаве алюминия марки AMg6 были экспериментально определены нами в предыдущей работе [23].

В настоящей работе эти исследования продолжены и дополнены измерениями механических (пределов прочности и пластичности) и нелинейных упругих характеристик (в том числе нелинейного акустического параметра N) в образцах поликристаллического сплава алюминия $\mathrm{AMg} 6$ и приготовленного из него нанокомпозита $n$ - $\mathrm{AMg} 6 / \mathrm{C}_{60}$.

\section{2. Материал и методики исследований}

В качестве исходного материала для получения нанокомпозита применялся поликристаллический промышленный сплав алюминия $\mathrm{AMg} 6$, соответствующий ГОСТ 4784-74. Образцы наноструктурного композита $n$ - $\mathrm{AMg6/ \textrm {C } _ { 6 0 }}$ были получены методом измельчения стружки исходного сплава в планетарной шаровой мельнице с добавлением 0.3 mass $\%$ фуллерита $\mathrm{C}_{60}$. Для предотвращения окисления и протекания других нежелательных реакций все манипуляции с исходными материалами и полученными порошками проводили в заполненном аргоном перчаточном боксе MBraun Unilab. Полученные порошки состояли из 50-200-микронных агломератов, представляющих собой совокупность наноразмерных кристаллитов. Исследование порошковых образцов методом рентгеновского когерентного рассеяния (CSL) показало, что средний размер кристаллитов составляет 40-60 nm [24]. После размола полученные порошки прессовались в брикеты цилиндрической формы диаметром $180 \mathrm{~mm}$ при температуре $250^{\circ} \mathrm{C}$ и давлении 200-300 МРа. Полученную заготовку подвергли прямой горячей экструзии при температуре $300^{\circ} \mathrm{C}$ с уменьшением площади поперечного сечения в 4 раза 

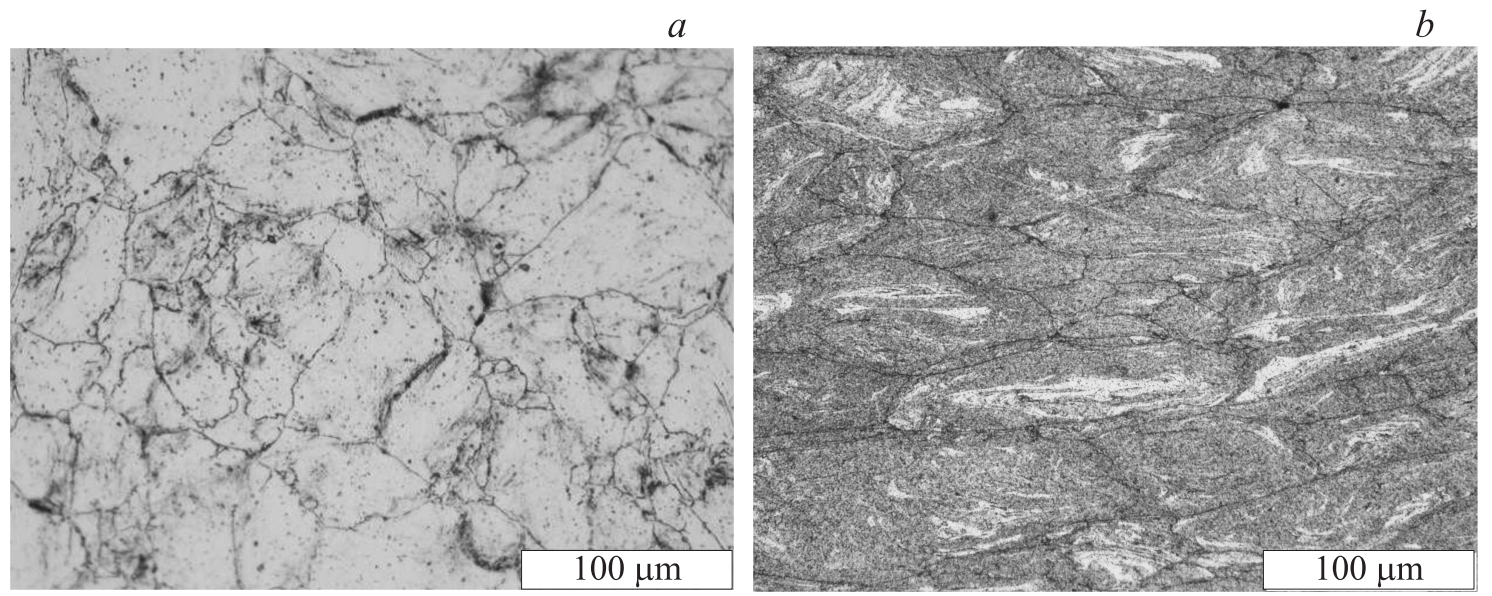

Рис. 1. Микроструктура образцов исходного сплава $\operatorname{AMg6}(a)$ и наноструктурного $n$ - $\mathrm{AMg} 6 / \mathrm{C}_{60}$ после экструзии $(b)$.

(сечение экструдированной заготовки $70 \times 70 \mathrm{~mm}$ ). На рис. 1 представлены результаты исследования микроструктуры исходного сплава $\mathrm{AMg} 6$ и наноструктурированного сплава $n$ - $\mathrm{AMg} 6 / \mathrm{C}_{60}$ после экструзии. Металлографические снимки поверхности образцов получены на микроскопе BX51 фирмы Olympus.

Из представленных на рис. 1 снимках видно, что после экструзии зерна алюминия ориентированы вдоль оси экструзии, поры между зернами отсутствуют. Исследование плотности методом гидростатического взвешивания показало, что плотность экструдированных образцов составляет $2.63 \pm 0.02 \mathrm{~g} / \mathrm{cm}^{3}$, что соответствует 99\% от удельной плотности сплава $\mathrm{AMg} 6$. Плотность образцов $n$-AMg6/C 60 измерялась с помощью весов KERN-770-60 с приставкой для измерения плотности „Sartorius YDK $01 \mathrm{LP}^{\star}$.

Стоит отметить, что микроструктура экструдированных нанокомпозитов наследует морфологию порошков после размола. На рис. 2 приведено изображение частиц порошка нанокомпозита $n-\mathrm{AMg} 6 / \mathrm{C}_{60}$ после размола,

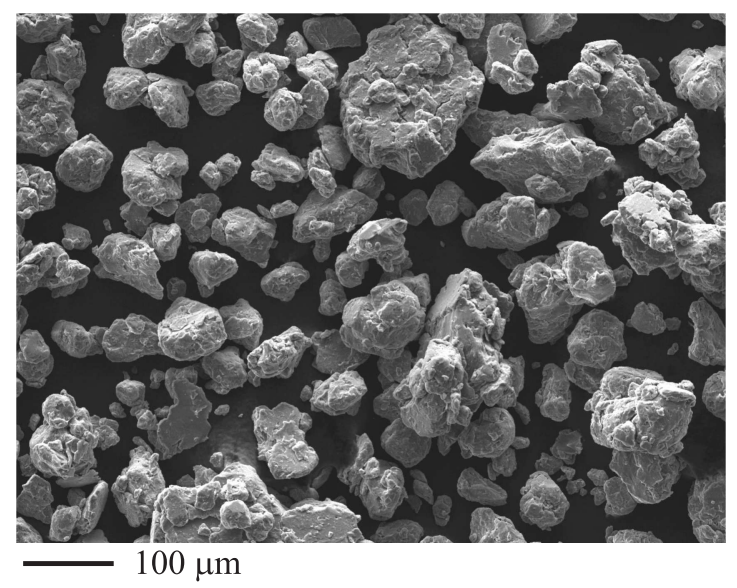

Рис. 2. СЭМ изображение частиц порошка нанокомпозита $n$ - $\mathrm{AMg} 6 / \mathrm{C}_{60}$ после размола. полученного с помощью сканирующего электронного микроскопа (СЭМ).

На представленном на рис. 2 изображении видно, что размер зерен в спеченом материале (рис. 1,b) соответствует размеру агрегатов и агломератов в порошке нанокомпозита (рис. 2). Такое наследование позволяет управлять структурой конечного нанокомпозита уже на этапе приготовления порошковых смесей, что открывает широкие возможности управления свойствами конечного материала.

Механические характеристики исследуемых материалов были измерены на универсальной испытательной машине Instron 5982 на образцах стандартной формы для испытаний на растяжение (диаметр шейки $4 \mathrm{~mm}$, длина $50 \mathrm{~mm}$ ), приготовленных из исходного сплава $\mathrm{AMg} 6$ и экструдированного $n-\mathrm{AMg} 6 / \mathrm{C}_{60}$. Общий вид экструдированных заготовок и приготовленных образцов для механических испытаний представлен на рис. 3 .

Для ультразвуковых измерений были приготовлены образцы из сплава алюминия $\mathrm{AMg6}$ и нанокомпозита $n$ - $\mathrm{AMg} 6 / \mathrm{C}_{60}$ в форме прямоугольных параллелепипедов с размерами сторон $\approx 20 \times 20 \times 40 \mathrm{~mm}$. Противоположные грани образцов полировались и были строго параллельны.

Экспериментальные исследования упругих свойств материалов в работе проводились на автоматизированной ультразвуковой установке, блок-схема которой приведена на рис. 4. Она состоит из ультразвукового автоматизированного комплекса Ritec RAM-5000 SNAP SYSTEM и системы для создания контролируемого одноосного сжатия в исследуемом образце. Для наблюдения за серией упругих импульсов в исследуемом образце использовался цифровой осциллограф DS09104A.

Комплекс Ritec RAM-5000 SNAP SYSTEM работает в импульсном режиме и предназначен для измерения линейных и нелинейных упругих свойств твердых тел.

Для исследования нелинейных упругих свойств твердых тел в комплексе реализован динамический спектральный метод, заключающийся в исследовании эф- 
a

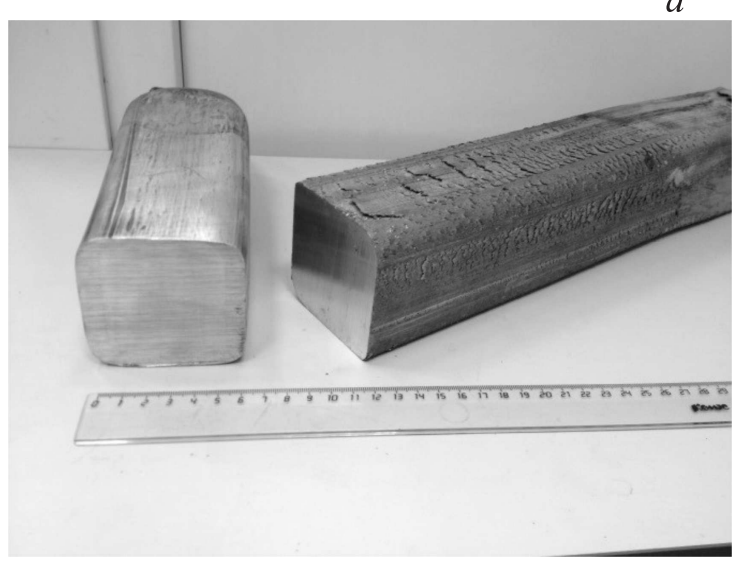

$b$

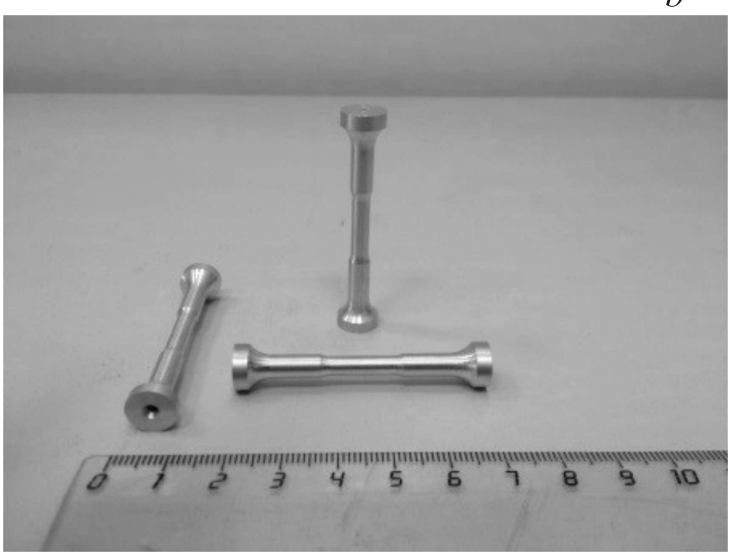

Рис. 3. Общий вид образцов $n-\mathrm{AMg6/C_{60 }}: a-$ после экструзии, $b-$ приготовленные образцы для испытаний на растяжение.

фективности генерации второй акустической гармоники на частоте $2 f=10 \mathrm{MHz}$ при распространении объемной акустической волны (ОАВ) конечной амплитуды на частоте $f=5 \mathrm{MHz}$. Комплекс позволяет измерять зависимость амплитуды второй гармоники от амплитуды первой гармоники ОАВ в автоматическом режиме.

При исследовании нелинейных упругих свойств сплавов спектральным методом использовались продольные ОАВ. Их возбуждение и прием проводился с помощью посеребренных пластинок из ниобата лития Y-36 ${ }^{\circ}$ среза с резонансными частотами 5 и $10 \mathrm{MHz}$. Пластинка c резонансной частотой $10 \mathrm{MHz}$ служила для приема ОАВ на частоте 5 и $10 \mathrm{MHz}$.

Для выделения сигналов первой и второй гармоник ОАВ комплекс снабжен комплектом фильтров низких и высоких частот.

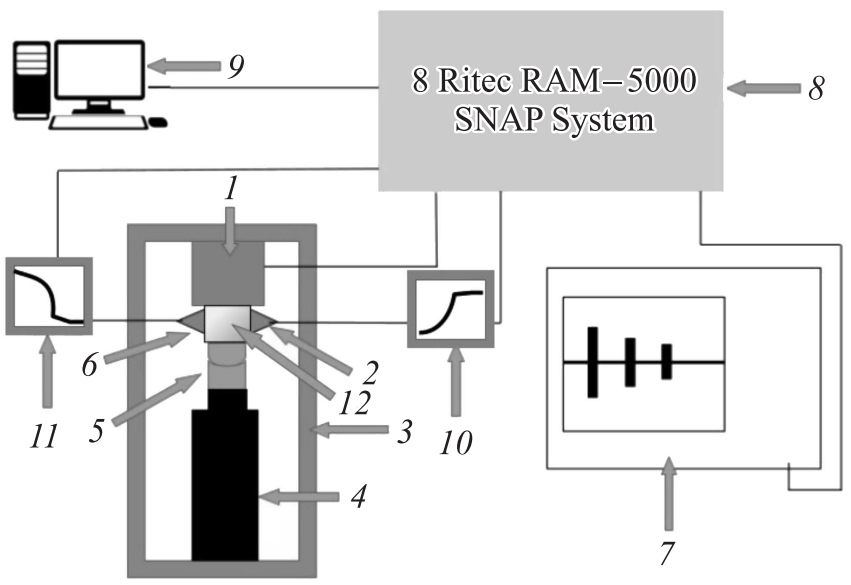

Рис. 4. Блок-схема автоматизированного ультразвукового комплекса: 1 - датчик давления, 2,6 - пьезоэлектрические преобразователи, 3 - рама, 4 - домкрат, 5 - сферический шарнир, 7 - осциллограф DSO7034B, 8 - ультразвуковой комплекс Ritec RAM-5000, 9 - компьютер, 10,11 - фильтры высоких и нижних частот соответственно.

\section{3. Экспериментальные результаты и их обсуждение}

3.1. Механические характеристики. На рис. 5 представлены типичные диаграммы деформации образцов исходного $\mathrm{AMg} 6$ (рис. $5, a$ ) и нанокомпозита $n$-AMg6/C 60 (рис. $5, b$ ).

Из представленных на рис. 5 данных видно, что условный предел текучести $\left(\sigma^{0.2}\right)$ при растяжении наноструктурированного образца $n-\mathrm{AMg} 6 / \mathrm{C}_{60}$ увеличился от значения $210 \mathrm{MPa}$ (для исходного сплава $\mathrm{AMg} 6$ ) до $640 \mathrm{MPa}$. Стоит отметить, что наряду с увеличением прочности наблюдается резкое падение пластичности наноструктурного $n$ - $\mathrm{AMg} 6 / \mathrm{C}_{60}$. Такое поведение характерно для наноструктурных материалов и связано с затруднением осуществления механизмов межзеренного проскальзывания и миграции дислокаций в объеме материала.

Отметим, что исследование механических характеристик, приготовленных ранее образцов, аналогичного наноструктурированному образцу $n$ - $\mathrm{AMg} 6 / \mathrm{C}_{60}$ были проведены в работе [5]. Измеренные механические свойства образцов материалов исследуемых в рамках данной работы, такие как предел текучести, прочность при растяжении, предельная деформация, совпали с данными работы [5] в пределах статистической погрешности.

3.2. Коэффициенты упругости второго порядка. КУВП определялись по результатам измерения скорости ОАВ в исследуемых образцах. При измерении скоростей ОАВ использовались стандартные пьезоэлектрические преобразователи, применяемые в неразрушающем контроле. Измерение скорости продольных ОАВ проводилось на частоте $10 \mathrm{MHz}$, а сдвиговых ОАВ на частоте $5 \mathrm{MHz}$. Ошибки при измерении скоростей ОАВ не превышали $0.5 \%$. Численные значения скоростей $\mathrm{OAB}$ в образце, измеренные вдоль трех направлений, параллельных ребрам образца, в пределах ошибок измерений совпали. Это позволило считать наши образцы изотропными. В изотропных твердых телах имеется 

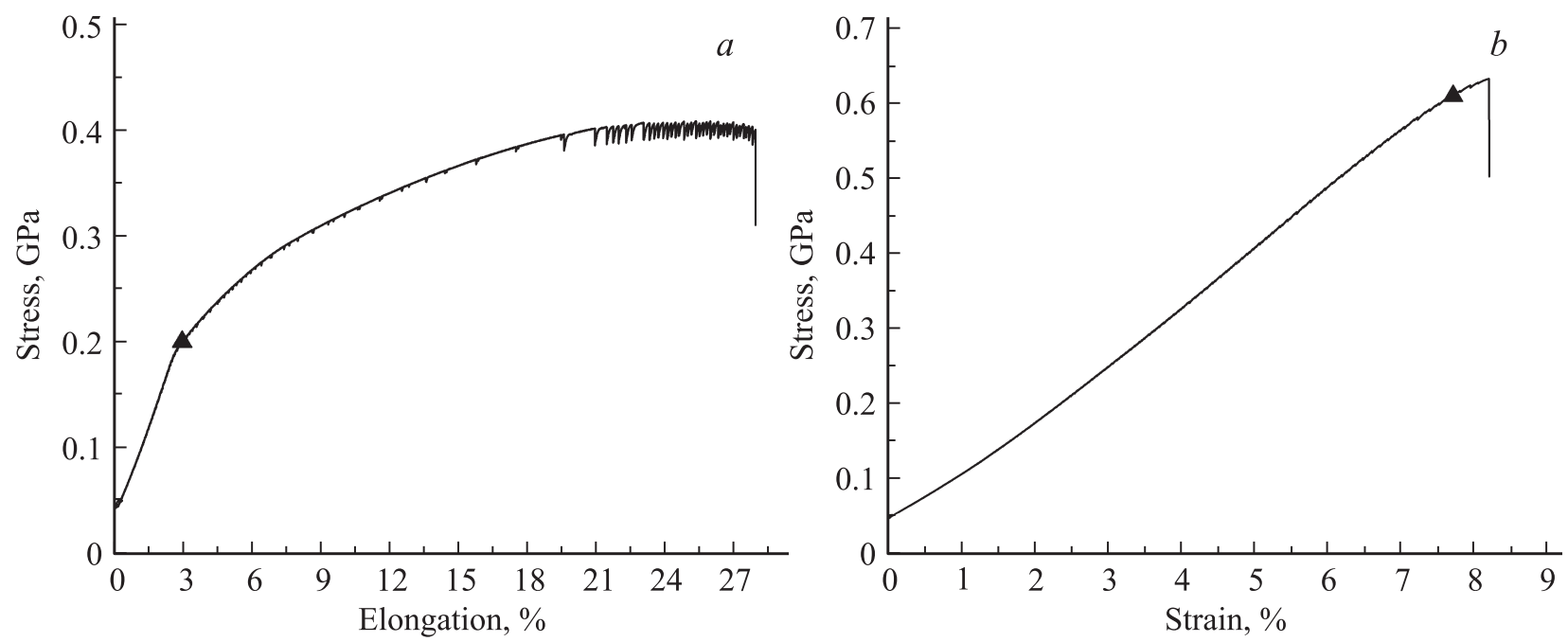

Рис. 5. Графики напряжение-деформация образцов исходного сплава $\operatorname{AMg} 6(a)$ и нанокомпозита $n$ - $\mathrm{AMg} 6 / \mathrm{C}_{60}(b)$.

12 отличных от нуля КУВП, но только 2 из них являются независимыми. Обычно такими принято считать коэффициенты $C_{11}$ и $C_{44}$ [25].

Измерения продольной $V_{L}=\sqrt{\left(C_{11} / \rho_{0}\right)}$, сдвиговой $V_{T}=\sqrt{\left(C_{44} / \rho_{0}\right)}$ скоростей ОАВ и плотности образцов $\rho_{0}$ позволили рассчитать в них (образцах) КУВП $C_{11}$ и $C_{44}$, модуль Юнга $E$, модуль объемного сжатия $B$, коэффициент Пуассона $\sigma$ и параметры Ламэ $\lambda, \mu=C_{44}$. Значения этих величин в образцах $\mathrm{AMg} 6$ и $n$ - $\mathrm{AMg} 6 / \mathrm{C}_{60}$ приведены в табл. 1. Как следует из таблицы, значения величин КУВП в образцах $\mathrm{AMg} 6$ и нанокомпозите $n$-AMg6/C 60 в пределах погрешностей их измерений совпадают. Это характерно практически для всех сплавов алюминия [1]. (В табл. 1 для сравнения приведены КУТП в сплаве алюминия В95).

3.3. Коэффициенты упругости третьего порядка. В [20] проанализировано распространение ОАВ малой амплитуды в однородно-деформированных твердых телах и получена система уравнений, позволяющая по результатам экспериментальных измерений зависимости скоростей ОАВ малой амплитуды в твердом теле от величины приложенного к нему одноосного сжа- тия $P$ и рассчитать все КУТП в исследуемом образце:

$$
\left[\frac{\partial\left(\rho_{0} W^{2}\right)}{\partial P}\right]_{P=0}=\left(2 \rho_{0} W^{2} F+G\right),
$$

где $W$ - „естественная скорость“ ОАВ, $\rho_{0}$ - плотность, $F=S_{j k a b}^{T} M_{a} M_{b} U_{j} U_{k}, \quad G=S_{i p a b}^{T} C_{j r k s i p} U_{j} U_{k} N_{r} N_{s} M_{a} M_{b}$, $S_{i p a b}^{T}$ - коэффициенты податливости второго порядка, $C_{\text {jrksip }}-$ КУТП в исследуемом материале, $U_{k}-$ компоненты вектора поляризации $\mathbf{U}, N_{r}$ - компоненты волнового вектора $\mathbf{N}, M_{i}$ - компоненты единичного вектора М в направлении одноосного сжатия. Предложенный в [20] метод для определения КУТП (метод Терстона-Браггера) является наиболее востребованным для определения КУТП в твердых телах. С помощью этого метода были определены КУТП как в анизотропных кристаллах, так и в ряде изотропных поликристаллических металлов: различных сортах стали, сплавах алюминия, вольфрама, молибдена [27-29].

В изотропном твердом теле имеется 18 отличных от нуля компонент тензора КУТП, но только три коэффициента: $C_{111}, C_{112}, C_{123}$ - считаются независи-

Таблица 1. Коэффициенты упругости второго порядка в нанокомпозите $\mathrm{AMg6/ \textrm {C } _ { 6 0 }}$ и сплавах алюминия $\mathrm{AMg6,} \mathrm{B} 95$

\begin{tabular}{|c|c|c|c|c|c|c|c|c|c|c|c|c|c|}
\hline \multirow{3}{*}{ Материал } & \multicolumn{2}{|c|}{$C_{i j} \cdot 10^{-10}, \mathrm{~N} / \mathrm{m}^{2}$} & \multicolumn{2}{|c|}{$S_{i j} \cdot 10^{12}, \mathrm{~m}^{2} / \mathrm{N}$} & \multirow{3}{*}{$\begin{array}{c}\mu \cdot 10^{-10}, \\
\mathrm{~N} / \mathrm{m}^{2}\end{array}$} & \multirow{3}{*}{$\begin{array}{c}\lambda \cdot 10^{-10} \\
\mathrm{~N} / \mathrm{m}^{2}\end{array}$} & \multirow{3}{*}{$\begin{array}{c}E \cdot 10^{-10} \\
\mathrm{~N} / \mathrm{m}^{2}\end{array}$} & \multirow{3}{*}{$\begin{array}{c}B \cdot 10^{-10}, \\
\mathrm{~N} / \mathrm{m}^{2}\end{array}$} & \multirow{3}{*}{$\sigma$} & \multirow{3}{*}{$\begin{array}{c}\rho, \\
\mathrm{kg} / \mathrm{m}^{3}\end{array}$} & \multirow{2}{*}{\multicolumn{2}{|c|}{$\begin{array}{c}\text { Скорость } \\
\text { акустических } \\
\text { волн, m/s }\end{array}$}} & \multirow{3}{*}{ Источник } \\
\hline & \multirow{2}{*}{$C_{11}$} & \multirow{2}{*}{$C_{44}$} & \multirow{2}{*}{$S_{11}$} & \multirow{2}{*}{$S_{12}$} & & & & & & & & & \\
\hline & & & & & & & & & & & $v_{L}$ & $v_{T}$ & \\
\hline$n-\mathrm{AMg} 6 / \mathrm{C}_{60}$ & $\begin{array}{c}10.2 \\
\pm 0.2\end{array}$ & $\begin{array}{c}2.55 \\
\pm 0.04\end{array}$ & $\begin{array}{c}14.7 \\
\pm 0.4\end{array}$ & $\begin{array}{c}-4.93 \\
\pm 0.1\end{array}$ & $\begin{array}{c}2.55 \\
\pm 0.04\end{array}$ & $\begin{array}{c}5.14 \\
\pm 0.08\end{array}$ & $\begin{array}{r}6.88 \\
\pm 0.1\end{array}$ & $\begin{array}{c}6.84 \\
\pm 0.06\end{array}$ & $\begin{array}{c}0.33 \\
\pm 0.01\end{array}$ & $\begin{array}{c}2598 \\
\pm 14\end{array}$ & $\begin{array}{r}6270 \\
\pm 60\end{array}$ & $\begin{array}{l}3130 \\
\pm 30\end{array}$ & $\begin{array}{l}\text { В наст. } \\
\text { работе }\end{array}$ \\
\hline AMg6 & $\begin{array}{c}10.6 \\
\pm 0.2\end{array}$ & $\begin{array}{c}2.59 \\
\pm 0.03\end{array}$ & $\begin{array}{c}14.2 \\
\pm 0.2\end{array}$ & $\begin{array}{l}-4.81 \\
\pm 0.07\end{array}$ & $\begin{array}{c}2.59 \\
\pm 0.03\end{array}$ & $\begin{array}{c}5.42 \\
\pm 0.08\end{array}$ & $\begin{array}{c}6.85 \\
\pm 0.07\end{array}$ & $\begin{array}{c}7.14 \\
\pm 0.06\end{array}$ & $\begin{array}{c}0.34 \\
\pm 0.01\end{array}$ & $\begin{array}{c}2630 \\
\pm 14\end{array}$ & $\begin{array}{r}6340 \\
\pm 60\end{array}$ & $\begin{array}{c}3140 \\
\pm 30\end{array}$ & [23] \\
\hline B95 & $\begin{array}{c}10.2 \\
\pm 0.3\end{array}$ & $\begin{array}{c}2.42 \\
\pm 0.04\end{array}$ & $\begin{array}{c}15.4 \\
\pm 0.5\end{array}$ & $\begin{array}{c}-5.28 \\
\pm 0.2\end{array}$ & $\begin{array}{c}2.42 \\
\pm 0.04\end{array}$ & $\begin{array}{c}5.36 \\
\pm 0.04\end{array}$ & $\begin{array}{c}6.51 \\
\pm 0.07\end{array}$ & $\begin{array}{c}6.97 \\
\pm 0.06\end{array}$ & $\begin{array}{c}0.34 \\
\pm 0.01\end{array}$ & $\begin{array}{c}2700 \\
\pm 15\end{array}$ & $\begin{array}{r}6140 \\
\pm 60\end{array}$ & $\begin{array}{c}3000 \\
\pm 30\end{array}$ & {$[22]$} \\
\hline
\end{tabular}



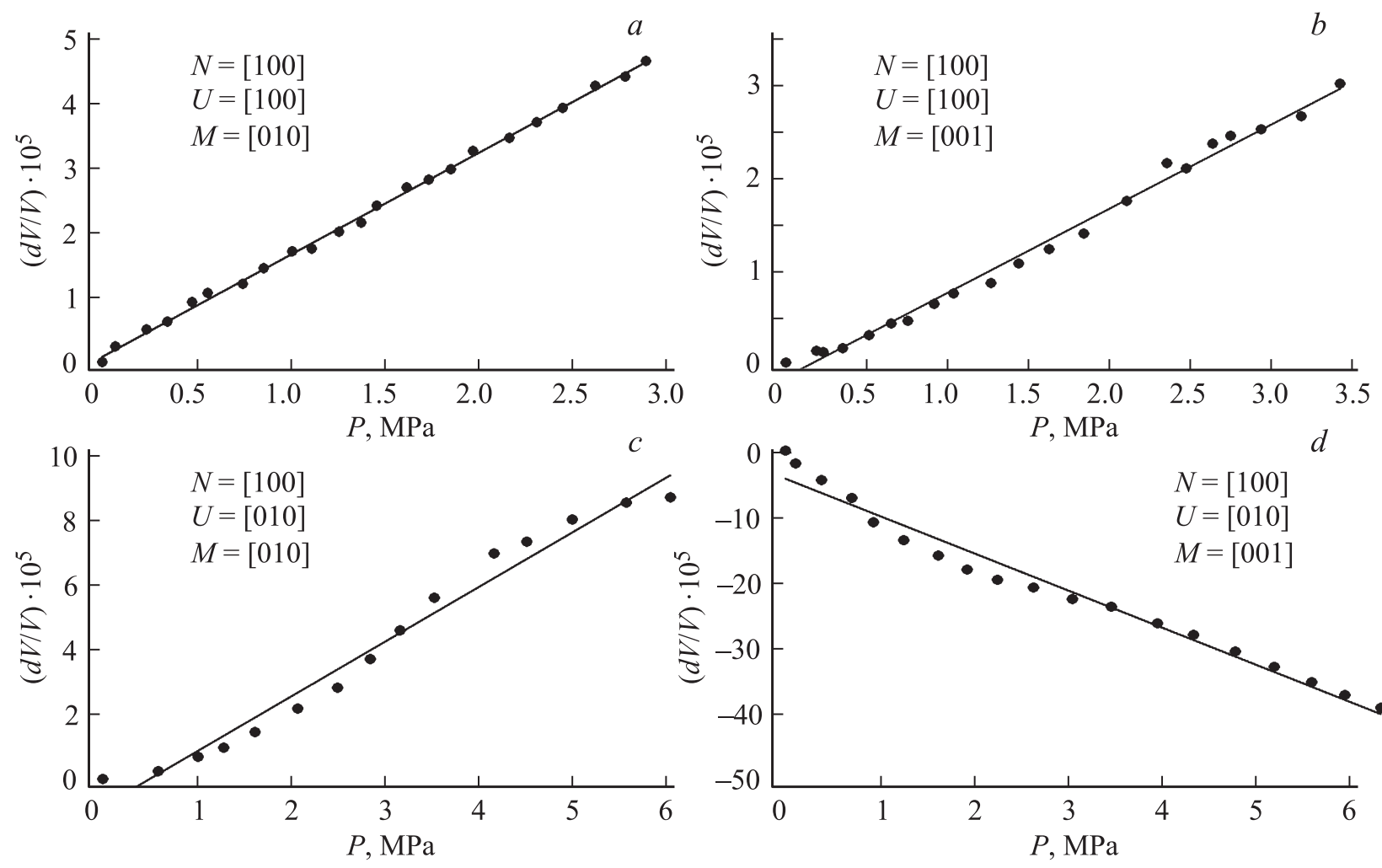

Рис. 6. Зависимости относительного изменения скоростей продольных и сдвиговых ОАВ от величины одноосного сжатия образца $P$ при различных направлениях единичных векторов $\mathbf{N}, \mathbf{U}, \mathbf{M}$ в образце нанокомпозита $n-\mathrm{AMg} 6 / \mathrm{C}_{60}$.

мыми, а остальные являются их линейной комбинацией [30]. Для определения трех независимых КУТП методом Терстона-Браггера в образцах нанокомпозита $n$-AMg6/C 60 были измерены зависимости относительного изменения скорости $(\Delta V / V)$ продольных и сдвиговых ОАВ от величины одноосного сжатия $P$ при различных направлениях единичных векторов $\mathbf{N}, \mathbf{U}$ и $\mathbf{M}$. Результаты этих измерений приведены на рис. 6.

Направление распространения упругой волны в образце и направление одноосного сжатия при всех измерениях были ортогональны. Для повышения точности определения трех независимых КУТП были проведены четыре измерения зависимости относительного изменения скорости в образце от величины одноосного сжатия $P$ в интервале $0-6 \mathrm{MPa}$. В этом интервале давлений зависимость относительного изменения скорости ОАВ $\Delta V / V$ от величины $P$, как видно из рис. 6 , линейна.

Экспериментальные зависимости, приведенные на рис. 6, были аппроксимированы прямыми линиями, тангенс угла наклона которых равен $\left(\frac{\partial(V)}{V \partial P}\right)_{P=0}$.

Эти измерения позволили определить в уравнении (2) численные значения

$$
\left(\frac{\partial\left(\rho_{0} W^{2}\right)}{\partial P}\right)_{P=0}=\left[2 \rho_{0} V^{2}\left(\frac{\partial V}{V \partial P}\right)\right]_{P=0}
$$

в $n-\mathrm{AMg} 6 / \mathrm{C}_{60}$ для всех случаев возможной взаимной ориентации векторов М, N, U. (Направление одноосного сжатия при всех измерениях было перпендикулярно направлению распространения упругой волны.) Результаты расчетов $\left(\frac{\partial\left(\rho_{0} W^{2}\right)}{\partial P}\right)_{P=0}$ приведены в табл. 2. В этой таблице также приведены свертки для $F, G$ в уравнении (2) для всех случаев взаимного расположения единичных векторов $\mathbf{N}, \mathbf{U}$ и $\mathbf{M}$, используемых при проведении экспериментов.

На основе экспериментально измеренных величин и соотношений, приведенных в табл. 2, была получена система из четырех линейных уравнений для определения трех независимых УПТП в образцах. Эта система была решена на компьютере методом наименьших квадратов и определены все три независимые КУТП: $C_{111}, C_{112}, C_{123}$ в образцах нанокомпозита $n$ - $\mathrm{AMg} 6 / \mathrm{C}_{60}$. Результаты расчетов КУТП приведены в табл. 3. В этой таблице для сравнения приведены КУТП для поликристаллических сплавов алюминия AMg6 [23], B95 [24].

Определенные значения КУТП $C_{111}, C_{112}, C_{123}$ в изотропных сплавах $\mathrm{AMg} 6$ и $n-\mathrm{AMg} 6 / \mathrm{C}_{60}$, позволили рассчитать альтернативные коэффициенты упругости третьего порядка в этих материалах: коэффициенты Мурнагана (Murnaghan), $l, m, n$ [31], Тупина-Берштейна (Toupin \& Bernstein) $v_{1}, v_{2}, v_{3}$ [32], Ландау $A, B, C[33]$. Результаты расчетов приведены в табл. 4. Величины погрешностей значений коэффициентов упругости третьего порядка, приведенных в табл. 4, не превышают $10 \%$. 
Таблица 2. Свертки для $\rho_{0} W^{2}, F, G$ и численные значения $\left(\frac{\partial\left(\rho_{0} W^{2}\right)}{\partial P}\right)_{P=0}$

\begin{tabular}{c|c|c|c|c|c|c|c}
\hline № & $N$ & $U$ & $M$ & $\rho_{0} W^{2}$ & $F$ & & $\left(\frac{\partial\left(\rho_{0} W^{2}\right)}{\partial P}\right)_{P=0}$ \\
\hline 1 & {$[100]$} & {$[100]$} & {$[001]$} & $C_{11}$ & $S_{12}$ & $S_{12} C_{111}+\left(S_{11}+S_{12}\right) C_{112}$ & 2.51 \\
2 & {$[100]$} & {$[010]$} & {$[010]$} & $C_{44}$ & $S_{11}$ & {$\left[\left(S_{11}+S_{12}\right) C_{111}-2 S_{12} C_{123}+\left(S_{12}-S_{11}\right) C_{112}\right] / 4$} & 0.945 \\
3 & {$[100]$} & {$[010]$} & {$[010]$} & $C_{44}$ & $S_{12}$ & {$\left[S_{12} C_{111}-S_{11} C_{123}-\left(S_{12}-S_{11}\right) C_{112}\right] / 4$} & -3.03 \\
4 & {$[100]$} & {$[100]$} & {$[010]$} & $C_{11}$ & $S_{12}$ & $S_{12} C_{111}+\left(S_{11}+S_{12}\right) C_{112}$ & 2.68
\end{tabular}

Таблица 3. Коэффициенты упругости третьего порядка в композите $n$ - $\mathrm{AMg} 6$ и сплавах алюминия $\mathrm{AMg} 6, \mathrm{~B} 95$ и $\mathrm{D} 16$ в $10^{11} \mathrm{~N} / \mathrm{m}^{2}$

\begin{tabular}{c|c|c|c|c}
\hline Материал & $C_{111}$ & $C_{112}$ & $C_{123}$ & Источник \\
\hline$n$-AMg6/C 60 & $-26.9 \pm 1.7$ & $-9.5 \pm 0.8$ & $-7.02 \pm 0.5$ & В наст. работе \\
$\mathrm{AMg6}$ & $-34.2 \pm 2.3$ & $-13.1 \pm 1.2$ & $-8.5 \pm 0.7$ & {$[23]$} \\
B95 & $-0.9 \pm 0.4$ & $1.68 \pm 0.25$ & $4.46 \pm 0.15$ & {$[34]$} \\
$\mathrm{D} 16$ & $-2.96 \pm 0.1$ & $-0.92 \pm 0.3$ & $2.38 \pm 0.3$ & {$[25]$}
\end{tabular}

Таблица 4. КУПТ $l, m, n, v_{1}, v_{2}, v_{3}, A, B, C$ в сплаве алюминия $\mathrm{AMg} 6$ и $n$-AMg6/C 60 в $10^{11} \mathrm{~N} / \mathrm{m}^{2}$

\begin{tabular}{c|c|c|c|c|c|c|c|c|c}
\hline Материал & $l$ & $m$ & $n$ & $v_{1}$ & $v_{2}$ & $v_{3}$ & $A$ & $B$ & $C$ \\
\hline AMg6 & -6.54 & -5.27 & -6.01 & -8.56 & -2.26 & -1.50 & -6.01 & -2.26 & -4.28 \\
$n$-AMg6/C 60 & -4.67 & -4.39 & -5.95 & -6.52 & -1.42 & -1.48 & -5.95 & -1.41 & -3.26
\end{tabular}

Таблица 5. Нелинейные параметры в сплаве $\mathrm{AMg} 6$ и образцах нанокомпозита $n$ - $\mathrm{AMg} 6 / \mathrm{C}_{60}$

\begin{tabular}{c|c|c|c|c|c}
\hline Материал & $A=M$ & $B$ & $N=3+C_{111} / C_{11}$ & $\left(\left|N / N_{n}\right|\right)_{\text {quasist }}$ & $\left(\left|N / N_{n}\right|\right)_{\text {spectr }}$ \\
\hline AMg6 & $2.068 \pm 0.002$ & $-9.91 \pm 0.06$ & $-31.3 \pm 0.2$ & & \\
$n-\mathrm{AMg6/C} 60$ & $2.097 \pm 0.006$ & $-10.11 \pm 0.03$ & $-25.6 \pm 0.2$ & $1.33 \pm 0.4$ & $1.22 \pm 0.1$
\end{tabular}

3.4. Исследования нелинейных упругих свойств твердых тел спектральным методом. Исследование нелинейных свойств твердых тел спектральным методом основано на экспериментальном измерении эффективности генерации высших акустических гармоник при распространении ОАВ конечной амплитуды в исследуемом образце $[11,16]$. В спектре гармонической продольной ОАВ конечной амплитуды, распространяющейся в изотропном твердом теле, кроме волны основной частоты $A_{f}=A_{1} \sin (2 \pi f t-k l)$, наблюдается волна второй гармоники ОАВ $A_{2 f}=$ $=A_{2} \sin [2(\omega t-k l)]$ :

$$
A=A_{1} \sin (\omega t-k l)+A_{2} \sin [2(\omega t-k l)] .
$$

Зависимость амплитуды второй гармоники $A_{2}$ от амплитуды продольной ОАВ первой гармоники $A_{1}$ в (3) определяется уравнением:

$$
A_{2}=\left[\left(N k^{2} L\right) A_{1}^{2}\right] / 8,
$$

где $k=\omega / V_{L}-$ волновое число, $L-$ длина области взаимодействия, $N=\left(C_{i j k \lg r}^{*}\right) / C_{i j k l}=\left(3 C_{11}+C_{111}\right) / C_{11}=$
$=\left(3+C_{111} / C_{11}\right)-$ нелинейный акустический параметр для продольной ОАВ в изотропном твердом теле, $k=2 \pi f / V_{L}-$ волновой вектор первой гармоники, $C_{11}$ - коэффициент упругости второго порядка (КУВП), $C_{111}$ - КУТП $[10,16]$.

Для анализа результатов экспериментов по генерации второй гармоники удобно амплитуды гармоник в (4) заменить на соответствующие им амплитуды деформаций

$$
\varepsilon=\left[\frac{\partial}{\partial x} A \sin (2 \pi F t-k a)\right]=-k A \cos (2 \pi F t-k a) .
$$

Откуда $A=\varepsilon / k$.

После подстановки (5) в (4) выражение связывающее амплитуду деформации в основной волне с амплитудой деформации во второй гармонике будет иметь вид:

$$
\varepsilon_{2 f}=\left[\left(|N|_{\text {spectr }} k L\right) / 4\right] \varepsilon_{f}^{M} .
$$

В уравнениях (4),(6) учтено, что в твердых телах с дефектами наряду решеточной и геометрической нелинейностями может присутствовать структурная нелинейность [14]. Вследствие этого зависимость амплитуды 

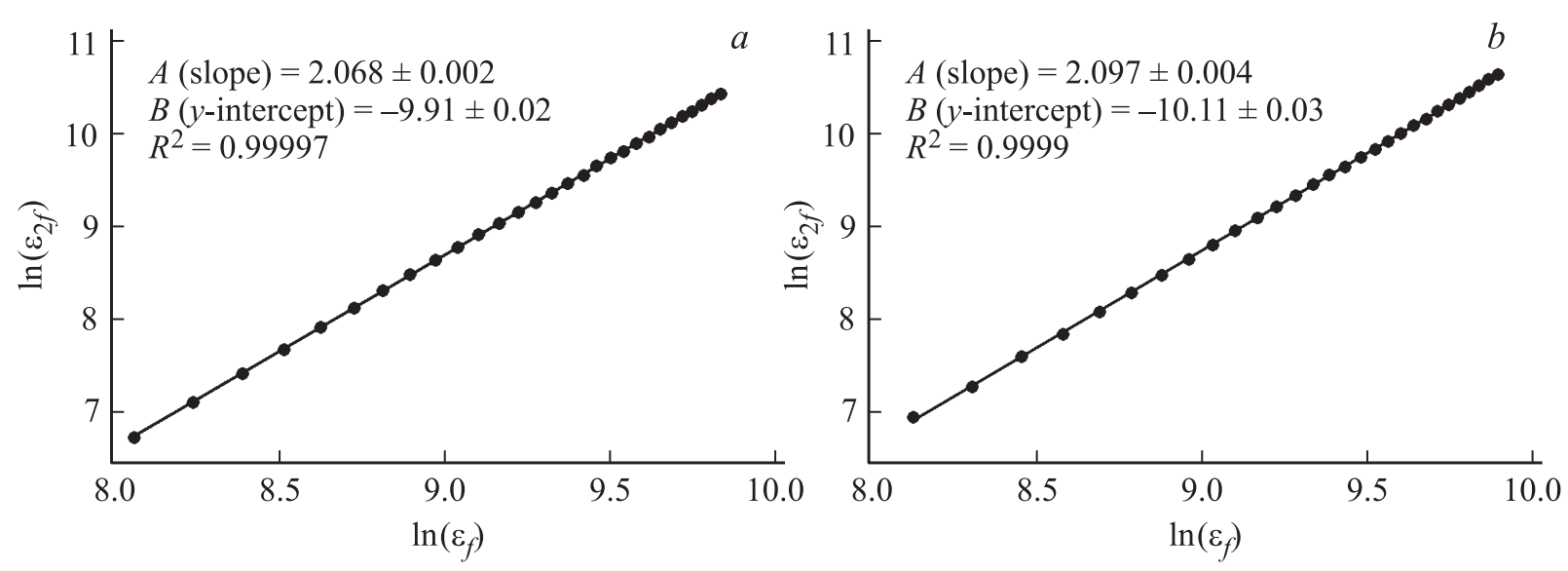

Рис. 7. Зависимость амплитуды второй акустической гармоники $\varepsilon_{2 f}$ от амплитуды первой гармоники $\varepsilon_{f}$ в сплаве $\mathrm{AMg} 6(a)$ и нанокомпозите $n-\mathrm{AMg} 6 / \mathrm{C}_{60}(b)$ в двойном логарифмическом масштабе.

деформации во второй гармонике $\varepsilon_{2 f}$ от амплитуды деформации в основной волне $\varepsilon_{f}$ в соотношениях (4), (6) может отличаться от квадратичной и в общем случае $M \neq 2$.

На рис. 7 приведены экспериментально измеренные зависимости амплитуд деформации второй гармоники $\varepsilon_{2 f}$ от амплитуды первой гармоники $\varepsilon_{f}$ для сплава $\mathrm{AMg} 6$ и нанокомпозита $n$ - $\mathrm{AMg} 6 / \mathrm{C}_{60}$ в двойном логарифмическом масштабе. Эти зависимости с высокой точностью аппроксимируются прямыми линиями, уравнение которых имеет вид

$$
Y=A X+B .
$$

После логарифмирования (6) получим:

$$
\ln \left(\varepsilon_{2 f}\right)=\ln \left[\left(|N|_{\text {spectr }} k L\right) / 4\right]+M \ln \varepsilon_{f} .
$$

Из сравнения выражений (7) и (8), следует: $Y=\ln \left(\varepsilon_{2 f}\right)$, $\left.X=\ln \left(\varepsilon_{f}\right), A=M, B=\left(|N|_{\text {spectr }} k L\right) / 4\right)$. Значения величин $A$ и $B$, определенные из результатов аппроксимации зависимостей, представленных на рис. 7 , приведены в табл. 5. В последнем столбце табл. 5 приведены значения величин нелинейных акустических параметров для продольной волны в тестируемых образцах, рассчитанные с использованием значений КУВП и КУТП, приведенных в табл. 1,2.

Необходимо также отметить следующее: экспериментально амплитуды первой и второй акустических гармоник измерялись по абсолютной величине и фазы этих величин не измерялись. Поэтому в (4) нелинейный акустический параметр $|N|_{\text {spectr }}$ записан по абсолютной величине.

В уравнениях (4),(6) также учтено, что в твердых телах с дефектами наряду решеточной и геометрической нелинейностями может присутствовать структурная нелинейность [14]. Вследствие этого зависимость амплитуды деформации во второй гармонике $\varepsilon_{2 f}$ от амплитуды деформации в основной волне $\varepsilon_{f}$ в (4), (6) может отличаться от квадратичной, поэтому, как уже отмечалось выше, в общем случае $M \neq 2$.
Воспользовавшись значениями параметра $D$, приведенными в табл. 4 для сплава AMg6 и нанокомпозита n-AMg6/C 60 , запишем следующие равенства:

$$
\begin{gathered}
B=\ln \left[\left(|N|_{\text {spectr }} k L\right) / 4\right]=9.91, \\
B_{n}=\ln \left[\left(\left|N_{n}\right|_{\text {spectr }} k L\right) / 4\right]=-10.11 .
\end{gathered}
$$

После вычитания выражения (8b) из (8a), получим

$$
B-B_{n}=\ln \left(\left|N / N_{n}\right|\right)_{\text {spectr }}=0.2 .
$$

Согласно (9) отношение нелинейных параметров по абсолютной величине для сплава AMg6 и композита $n$-AMg6/C 60 , определенных из спектральных измерений, равно

$$
\left|N / N_{n}\right|_{\text {spectr }}=\exp (0.2)=1.22 \pm 0.2,
$$

где индексом „, $n^{\text {“ } о б о з н а ч е н ы ~ в е л и ч и н ы ~ д л я ~ к о м п о з и т а ~}$ $n$-AMg6/C 60 , без индекса - величины для сплава AMg6.

Аналогичная величина, рассчитанная с использованием значений КУВП и КУТП, приведенных в табл. 1,2, равна $\left|N / N_{n}\right|_{\text {quasist }}=1.33 \pm 0.4$. Т. е. отношения нелинейных параметров $\left|N / N_{n}\right|$, определенных из квазистатических измерений КУТП методом Терстона-Браггера и из спектральных измерений в образцах сплава $\mathrm{AMg} 6$ и композита $n$ - $\mathrm{AMg} 6 / \mathrm{C}_{60}$ в пределах ошибок измерения величин, приведенных в табл. 1-3, совпадают. Это указывает на то, что численные значения КУТП для этих материалов определены корректно.

\section{4. Заключение}

B поликристаллических сплавах алюминия AMg6 и нанокомпозита $n$ - $\mathrm{AMg} 6 / \mathrm{C}_{60}$ изучены механические и, ультразвуковым методом, линейные и нелинейные упругие свойства.

Изменения механических характеристик при наноструктурировании весьма значительно. Предел прочности сплава при этом увеличился в три раза с одновременным падением пластичности. 
По результатам измерения скорости упругих продольных и сдвиговых ОАВ методом Терстона-Браггера в образцах нанокомпозита $n$-AMg6/C 60 были определены все независимые КУТП. (Для исходного сплава $\mathrm{AMg} 6$ КУВП и КУТП были определены нами ранее и представлены в [23]). Нелинейные упругие свойства образцов алюминиевого сплава $\mathrm{AMg} 6$ и нанокомпозитного сплава $n$-AMg6/C 60 были исследованы и спектральным методом. Для этого были измерены зависимости амплитуд второй акустической гармоники от амплитуды основной гармоники упругой волны в этих образцах. Было установлено, что показатель степени $M$, определяющий степенную зависимость амплитуды второй гармоники упругой волны от амплитуды основной гармоники в исследованных нами образцах, в отличие от бездефектных сред, не равен двум. Это указывает на наличие в образцах $\mathrm{AMg} 6$ и нанокомпозита $n-\mathrm{AMg} 6 / \mathrm{C}_{60}$ дефектов и остаточных напряжений, возникших при изготовлении образцов для исследований. Анализ коэффициентов упругости второго порядка в различных сплавах алюминия, приведенных в [1,2], показывает, что величины этих коэффициентов в пределах ошибки в 15-20\%, как правило, совпадают. В [26] были определены КУВП в алюминиевых сплавах В95 (система $\mathrm{Al}-\mathrm{Zn}-\mathrm{Mg}-\mathrm{Cu}$ ). Анализ величин КУВП показывает, что их отличие в сплавах $\mathrm{AMg} 6, n-\mathrm{AMg} 6 / \mathrm{C}_{60}$, B95 не превышает 30\% для $C_{11}$ и $10 \%$ для $C_{44}$. Однако значения КУТП в сплавах $\mathrm{AMg} 6, n$-AMg6/C 60 , В95 отличаются в разы или даже в десятки раз (табл. 3,4). Так, например, величина коэффициента $C_{111}$ в сплаве $\mathrm{AMg} 6$ примерно в полтора раза больше величины этого коэффициента в образцах нанокомпозитного сплава $n-\mathrm{AMg} 6 / \mathrm{C}_{60}$. В сплаве $\mathrm{B} 95$ коэффициент $C_{111}$ более чем в 3 раза меньше аналогичного коэффициента в сплаве Д16, и почти в 20 раз меньше коэффициента $C_{111}$ в сплаве $\mathrm{AMg} 6$.

Это указывает на то, что КУТП более чувствительны к химическому составу, структуре, стехиометрии материала, чем КУВП, а наноструктурирование материала приводит к значительным изменениям как пределов прочности и текучести, так и нелинейных упругих характеристик - КУТП и нелинейного акустического параметра.

\section{Список литературы}

[1] В.А. Брострем, Н.А. Буше. Конструкционные материалы. Справочник / Под ред. Б.Н. Арзамасова. Машиностроение, M. (1990). 688 c.

[2] А.П. Бабичев, Н.А. Бабушкина, А.М. Братковский. Физические величины. Справочник / Под ред. Е.С. Григорьева, Е.3. Мейлихова. Энергоатомиздат, М. (1991). 1232 с.

[3] Р.3. Валиев, И.В. Александров. Объемные наноструктурные металлические материалы: получение, структура и свойства. ИКЦ Академ. книга, М. (2007). 398 с.

[4] В.Н. Чувильдеев, М.Ю. Грязнов, В.И. Копылов, А.Н. Сысоев, Б.В. Овсянников, А.А. Флягин. Вестн. Нижегородского ун-та им. Н.И. Лобачевского 4, 35 (2008).
[5] N. Lvova, I. Evdokimov, S. Perfilov. Adv. Mater. Res. 1119, 9 (2015).

[6] E.O. Hall. Proc. Phys. Soc. London 64, 747 (1951).

[7] N.J. Petch. J. Iron Steel Inst. London 173, 25 (1953).

[8] Г.А. Малыгин. ФТТ 49, 961 (2007).

[9] Т.П. Черняева, В.М. Грицина, Е.А. Михайлов, А.В. Остапов. Вопросы атомной науки и техники. Серия: Физика радиационных повреждений и радиационное материаловедение 4-2, 206 (2009).

[10] S.F. Pugh. Philosoph. Mag. 45, 823 (1954).

[11] Y. Song, R. Yang, D. Li, Z.X. Guo. Philosoph. Mag. 81, 321 (2001).

[12] V.M. Prokhorov, V.D. Blank, R.H. Bagramov, S.A. Perfilov, G.I. Pivovarov. AIP Conf. Proc. 1569, 389 (2013).

[13] Д. Такер, В. Рэмптон. Гиперзвук в физике твердого тела. Мир, М. (1975). 454 с.

[14] Л.К. Зарембо, В.А. Красильников. Введение в нелинейную акустику. Наука, М. (1966). 519 с.

[15] Ю.А. Бражкин, А.И. Коробов, В.А. Красильников, В.Е. Лямов. ФТТ 18, 1746 (1976)

[16] О.В. Руденко. УФН 176, 77 (2006).

[17] О.В. Руденко. Дефектоскопия 8, 24 (1993).

[18] Л.К. Зарембо, В.А. Красильников, В.А. Румянцева, О.Ю. Сердобольская. Акуст. журн. 41, 784 (1995).

[19] Л.К. Зарембо, В.А. Красильников, И.Е. Школьник. Дефектоскопия 10, 76 (1989).

[20] R.N. Thurston, K. Brugger. Phys. Rev. 133, PA1604 (1964).

[21] M.A. Breazeale, J. Philip. In: Physical Acoustics: Principles and Methods. / Ed. W.P. Mason, R.N. Turston. Academic, N.Y. (1984). V. XVII. P. 2.

[22] Н.П. Кобелев, Е.Л. Колыванов, В.А. Хоник. ФТТ 57, 1457 (2015).

[23] А.Д. Волков, А.И. Кокшайский, А.И. Коробов, В.М. Прохоров. Акуст. журн. 61, 685 (2015).

[24] A. Zameshin, M. Popov, V. Medvedev, S. Perfilov, R. Lomakin, S. Buga, V. Denisov, A. Kirichenko, E. Skryleva, E. Tatyanin, V. Aksenenkov, V. Blank. Appl. Phys. A 107, 863 (2012).

[25] Э. Дьелесан, Д. Руайе. Упругие волны в твердых телах. Наука, М. (1975). 680 с.

[26] А.И. Коробов, В.М. Прохоров, Д.М. Мехедов. ФТТ 55, 10 (2013).

[27] R.T. Smith, R. Stern, W.B. Sternes. J. Acoust. Soc. Am. 40, 1002 (1966).

[28] А.И. Коробов, Б.Б. Воронов. ФТТ 38, 2159 (1996).

[29] А.И. Коробов, В.М. Прохоров, О.Ю. Сердобольская, П. Хегедуш. Кристаллография 23, 566 (1978).

[30] Ю.И. Сиротин, М.П. Шаскольская. Основы кристаллоакустики. Наука, М. (1975). 680 с.

[31] F.D. Murnaghan. Finite Deformations of an Elastic Solid. Chapman \& Hall, N.Y. (1951).

[32] R.A. Toupin, B. Bernstein. J. Acoust. Soc. Am. 33, 216 (1961).

[33] Л.Д. Ландау, Е.М. Лифшиц. Механика сплошных сред. Гостехиздат, М. (1953).

[34] А.И. Коробов, А.В. Батенев, Ю.А. Бражкин. Дефектоскопия 2, 39 (2000). 